\title{
Effect of ultrasonic impact treatment (UIT) on fatigue strength of welded joints
}

\author{
T.Suzuki ${ }^{1, a^{*}}$, T.Okawa $^{2}$, H.Shimanuki ${ }^{3}$, T.Nose $^{3}$ N.Ohta ${ }^{4}$, H.Suzuki ${ }^{5}$, A.Moriai ${ }^{5}$ \\ ${ }^{1}$ Advanced Technology Research Laboratories, Nippon Steel and Sumitomo Metal Corporation, \\ Japan \\ ${ }^{2}$ Oita R\&D Laboratories, Nippon Steel and Sumitomo Metal Corporation, Japan \\ ${ }^{3}$ Steel Research laboratories, Nippon steel and Sumitomo Metal Corporation, Japan \\ ${ }^{4}$ Futtsu Unit, Nippon Steel \& Sumikin Technology Co., LTD., Japan \\ ${ }^{5}$ Quantum Beam Science Directorate, Japan Atomic Energy Agency, Japan \\ aemail : suzuki.3c.tamaki@jp.nssmc.com
}

Keywords: residual stress, ultrasonic impact treatment, UIT, fatigue strength, neutron, welded joints, X-ray, surface residual stress, internal residual stress, surface stress concentration

\begin{abstract}
Ultrasonic impact treatment(UIT) is a remarkable post-weld treatment, which reduce not only in external stress concentration, but also in residual stress in a welded joints. Internal and surface stresses were investigated on UIT treated welded joints by neutron and X-ray diffraction method. This paper discuses the effect of internal and surface residual stress and surface stress concentration after UIT on fatigue resistance by the comparison of fatigue experiments to predictions calculated with the results of the experimental investigations.
\end{abstract}

\section{Introduction}

Steel structures are often subjected to cyclic loading, such as traffics. Sometimes these structures are damages by such cyclic loadings even if the stress induced by the loads are much smaller than yield stress. This type of the damage is called fatigue fracture. In general, fatigue strength falls greatly and in most cases the fatigue are found at a near-weld-toe-area, and it is well known that the fatigue life of welded joints is little influenced by the strength of steels but influenced by the residual stress and the high stress concentration near the weld toe. Thus, it is important to control the stress condition at this near-weld-toe-areas. To control the stress condition at the near-weld-toe-area, various methods such as grinding, tungsten inter gas(TIG) dressing, hammer peening, shot peening, laser peenig, low transformation temperature(LTT) welding consumable, have been developed and applied to weld toe[1-5]. However, none of them can be said to be wholly satisfactory. Ultrasonic impact treatment(UIT) is a remarkable post-weld treatment, which convert ultrasonic wave to mechanical impact oscillations and peening the metal surface and give plastic deformation, and reduce in not only the external stress concentration through the formation of a smooth transition at the weld toe, but also in residual welding tensile stress and create favourable surface compressive stresses at the near-weld-toe-area and improve fatigue life [6-9]. Fig. 1 shows the UIT system. UIT is a registered trademark of Applied Ultrasonics,LCC.

UIT modify residual stress of not only the surface but also the

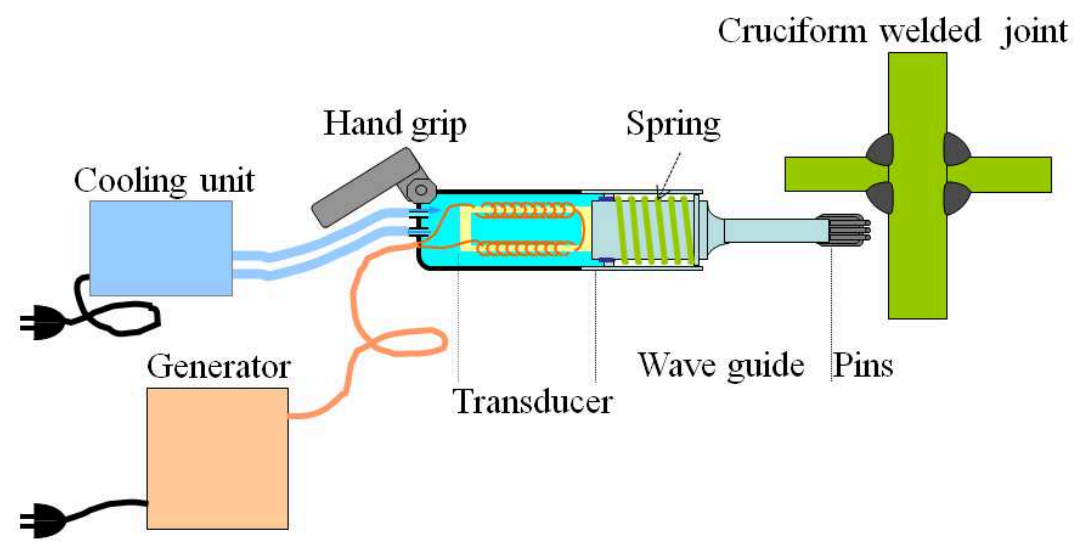

Fig. 1. UIT system. 
internal, but it is not clear. So, the motivation of this study is to clarify the internal stress conditons after UIT, and understand the effect of internal stress distribution on fatigue resistance, and final goal is to know how to control stress conditions by UIT to improve fatigue life of steel structure effectively. For this aim, it is important to know both the internal and surface stress conditions after UIT. Internal and surface stresses were investigated on UIT treated welded joints by neutron and X-ray diffraction method[10,11]. This paper discuses the effect of internal and surface residual stress and surface stress concentration after UIT on fatigue resistance by the comparison of fatigue experiments to predictions calculated with the results of the experimental investigations.

\section{Experimental Procedures}

\section{Specimens.}

The non-load-carrying cruciform joints were welded using CO2 fillet welding with SM490 base metal plates according to JIS G 3106 and T49J0T1-1CA-UH5 flux-cored welding wire according to JIS Z 3313. The dimensions of the specimen joints used for this study are shown in Fig. 2. UIT is applied to the weld toes of some specimens. The treatment was conducted using an Esonic ${ }^{\mathrm{TM}} 27$ UIS made by Applied Ultrasonic and pins designed exclusively for UIT use $(3 \mathrm{~mm}$ tip radius and $3 \mathrm{~mm}$ diameter) under the following conditions: frequency, $27 \mathrm{kHz}$; power output, roughly $1 \mathrm{~kW}$; shifting speed, roughly $10 \mathrm{~mm} / \mathrm{sec}$.

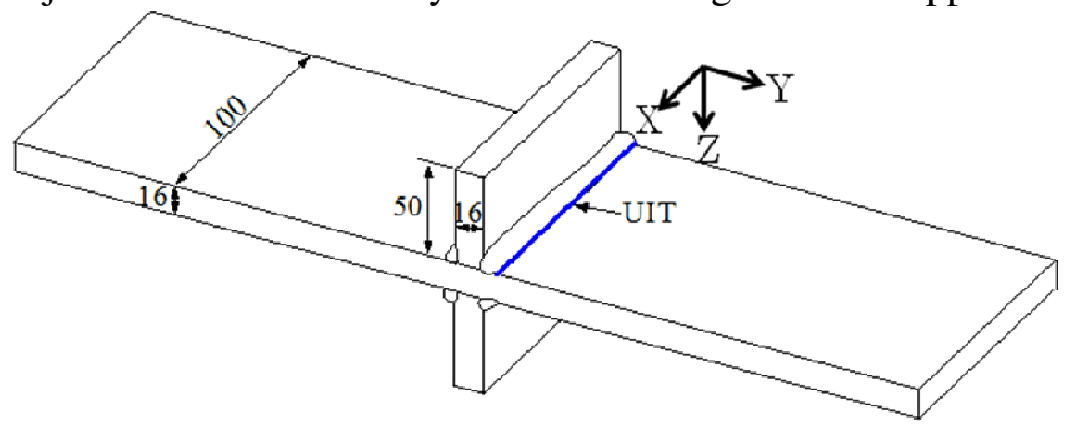

Fig. 2. Cruciform welded joint.

\section{Fatigue tests.}

The fatigue tests were conducted for the specimens without and with UIT under the constant-amplitude loading in the stress range of $80 \sim 280 \mathrm{MPa}$ and at a stress ratio of 0.1 . For the experimental results, the number of loading cycles along the abscissa represents that cycle at which the specimen actually broke.

Non-destructive surface shape evaluation by Laser.

The sectional shapes of a weld bead of the cruciform welded joins before and after UIT were measured by Laser Displacement sensor.

\section{Estimation of surface external stress concentration.}

The stress concentration coefficient Kt for the cruciform welded joints before and after UIT are calculated using the estimation formula proposed by Tsuji with the weld toe radius $\rho$ and other local dimension parameters of the joint[12].

\section{Non-destructive surface stress evaluation by $X$-ray diffraction method.}

We performed non-destructive surface stress measurements by X-ray diffraction method. The surface stress at the weld-toe after UIT was determined by the $\sin ^{2} \psi$ method using a conventional laboratory X-ray equipment. The Fe 211 diffraction by the characteristic X-ray of $\mathrm{Cr}-\mathrm{K} \alpha$ radiation was used for stress measurements. For the comparison, we also measured a surface stress at the weld-toe before UIT.

\section{Non-destructive internal stress evaluation by neutron diffraction method.}

We performed non-destructive surface stress measurements by the neutron diffraction method using a diffractometer for residual stress analysis (RESA) at the JAEA. For the purpose of stress measurements, $\alpha$-Fe211 diffraction was used. The wavelength, $\lambda$, of the neutron beam used was approximately $1.65 \AA$ and he diffraction angle, $2 \theta$, was approximately $90 \mathrm{deg}$. A $2 \mathrm{~mm} \times 2 \mathrm{~mm}$ slit was used as the receiving slit. Under those conditions, the gauge volume at the measuring position was set to be approximately $2 \times 2 \times 2 \mathrm{~mm}^{3}$. Residual stress was evaluated in three directions, $\mathrm{X}, \mathrm{Y}$ and Z, which are shown in Fig. 2. In the neutron diffraction method, a lattice constant under the stress-free 
condition is required when it comes to conducting triaxial stress analysis based on the measurement results for lattice plane spacings in three directions. For a specimen prepared under the same conditions as the specimen measured, the lattice constant that is obtained with a coupon sample prepared by electrical discharge machining at the same point as the measuring points was used as the lattice constant under stress-free

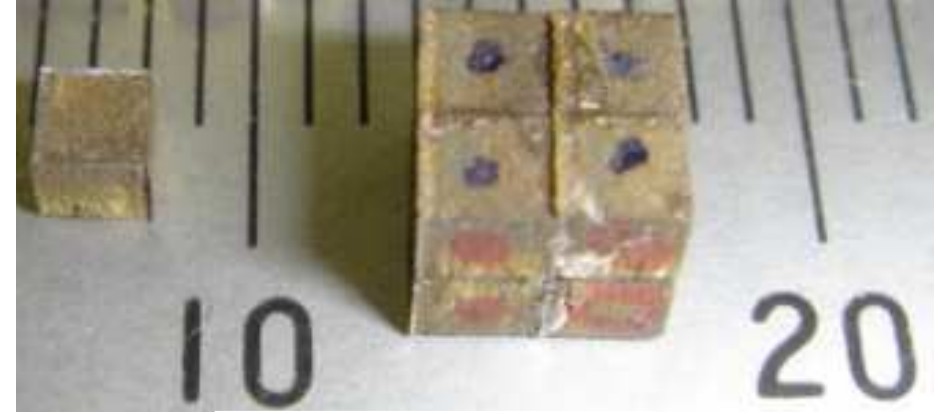

Fig.3. Coupon samples. conditions. Prepared coupon samples are shown in Fig.3. Using the lattice constants decided by the above method as the lattice constants under stress-free conditions, a0, we conducted a strain and stress analysis using Eq. 1 and Eq. 2 below. In Eq. 1 and Eq. 2, $\varepsilon, \sigma, \mathrm{E}_{110}$ and $v_{110}$ denote strain, stress, Young's modulus and Poisson's ratio, respectively, for the 110 diffraction. We used $224 \mathrm{GPa}$ as $\mathrm{E}_{110}$ and 0.276 as $v_{110}$.

$$
\begin{aligned}
\varepsilon_{\mathrm{i}}=\left(\mathrm{a}_{\mathrm{i}}-\mathrm{a}_{0}\right) / \mathrm{a}_{0} . & (\mathrm{i}=\mathrm{X}, \mathrm{Y}, \mathrm{Z}) \\
\sigma_{\mathrm{i}}=\mathrm{E}_{110} /\left(1+v_{110}\right)\left\{\varepsilon_{\mathrm{i}}+v_{110} /\left(1-2 v_{110}\right)\left(\varepsilon_{\mathrm{X}}+\varepsilon_{\mathrm{Y}}+\varepsilon_{\mathrm{Z}}\right)\right\} . & (\mathrm{i}=\mathrm{X}, \mathrm{Y}, \mathrm{Z})
\end{aligned}
$$

\section{Experimental Results}

\section{Fatigue tests.}

Fig. 4 shows the experimental S-N curves (stress versus number of loading cycles to failure) obtained with the fatigue test results. In the high cycle fatigue conditions that the stress range are small, then the fatigue life of the specimens to which the UIT was applied were about forty times of that of those without the UIT(As-weld). On the other hands, in the low cycle fatigue conditions that the stress range is large, the fatigue life improvement effect of the UIT tended to be lower than that in the low cycle fatigue conditions.

Surface shape evaluation by Laser.

The sectional shapes of a weld bead before and after UIT are shown in Fig. 5. Befor UIT for a as-weld specimen, the sectional shapes of a weld bead toe radius $\rho$ was roughly $0.25 \mathrm{~mm}$. After UIT, it increased to roughly $2.0 \mathrm{~mm}$ through the formation of a smooth transition at the weld toe.

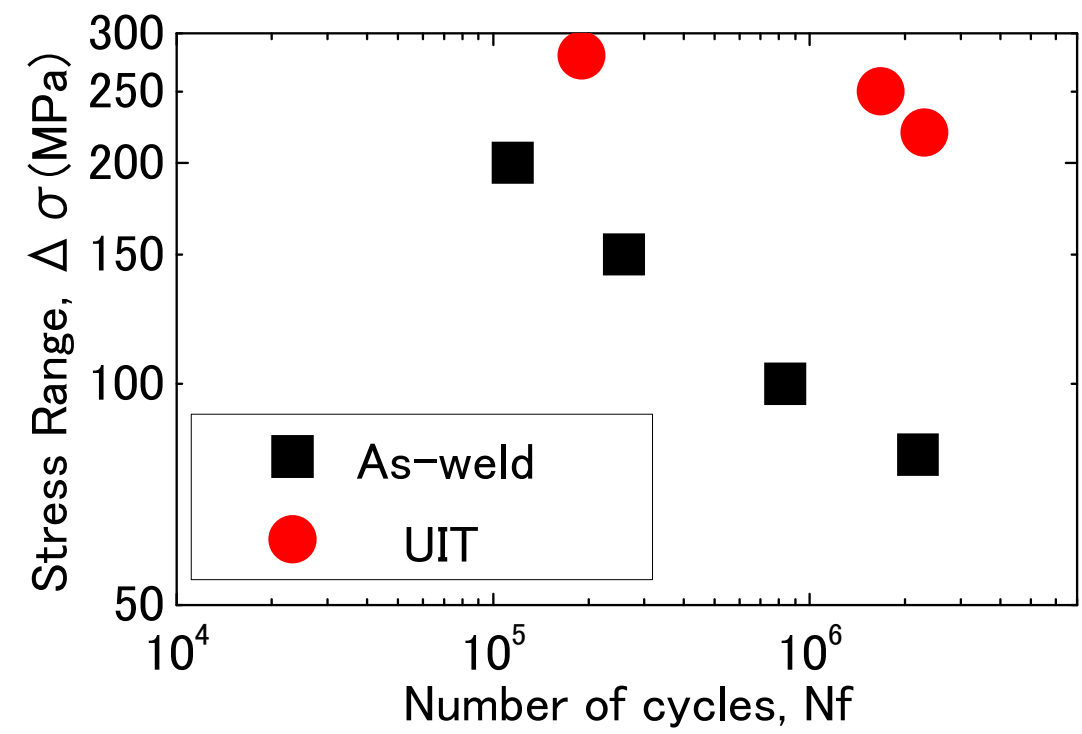

Fig. 4. Experimental S-N curves

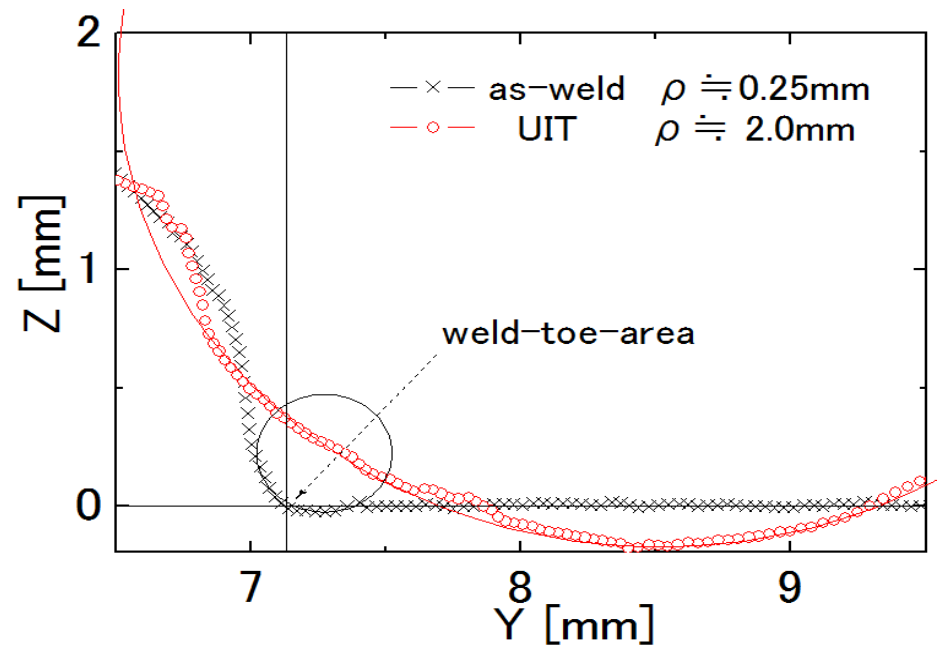

Fig. 5. Shapes of a weld bead before and after UIT 
Estimation of surface external stress concentration.

Using the measurement values of weld toe radius, the stress concentration coefficient $\mathrm{Kt}$ for the cruciform welded joints before and after UIT were calculated to 4.07 and 2.16, respectively.

Non-destructive surface stress evaluation by $\mathrm{X}$-ray diffraction method.

The surface stress at the weld-toe before UIT determined by the $\sin ^{2} \psi$ method using a conventional laboratory X-ray equipment was $227 \mathrm{MPa}$. This large residual tensile stress was supposed to be produced by the procedure that the weld metal has been locally heated and melted during welding, cooled and shrunk at the end of welding under constraint from the surrounding members. The surface stress at the weld-toe after UIT was $-76 \mathrm{MPa}$. This residual compressive stress was supposed to be introduced by a plastic flow which has been generated when the pin was pressed against the weld toe.

Non-destructive

internal stress

evaluation by neutron diffraction method.

Fig. 6 shows the results of internal residual stress evaluation at weld-toe-area of a cruciform welded joint before UIT (as-weld) by neutron diffraction method. Before UIT, surface is residual tensile stress and internal is residual compression. This surface residual tensile stress was supposed to be produced by the procedure that the weld metal has been locally heated and melted during welding, cooled and shrunk at the end of welding under constraint from the surrounding members.

Fig. 7 shows the results of internal residual stress evaluation at weld-toe-area of a cruciform welded joint after UIT by neutron diffraction method. After UIT, stress distribution is completely changed,

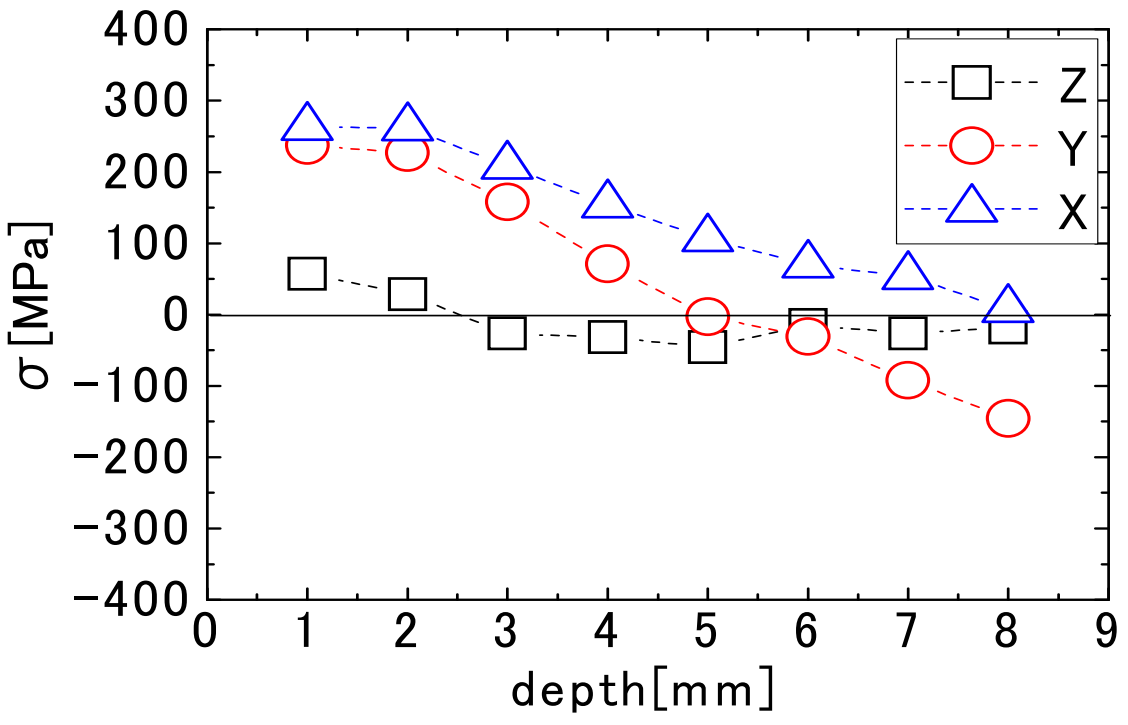

Fig. 6. Internal stress distribution before UIT.

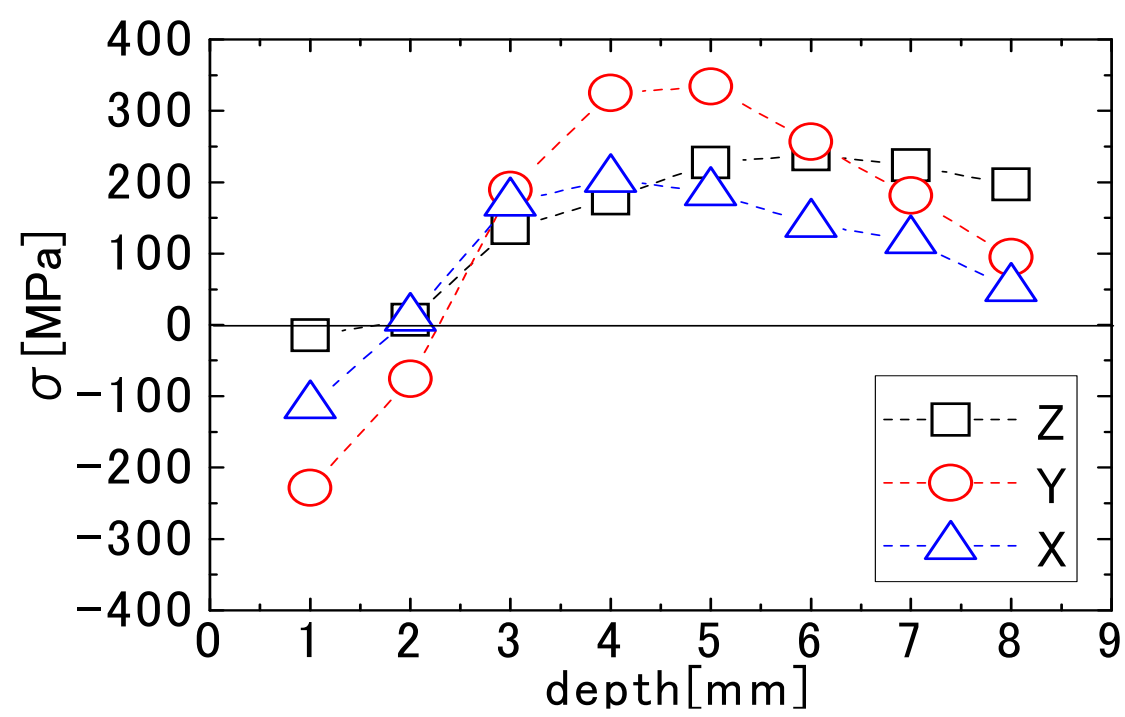

Fig. 7. Internal stress distribution after UIT. surface is residual compressive stress and internal is residual tensile stress. The surface residual compressive stress after UIT was supposed to be introduced by a plastic flow which has been generated when the pin was pressed against the weld toe. 


\section{Discussions}

\section{Estimation of fatigue life.}

The Locally-Expanded Modified Goodman Diagram (LEMGD) that takes into account the steel strength, local stress concentration and local residual stress, and that permits estimating the fatigue life from calculated fatigue strength, is a simple technique to estimate fatigue life[13,14]. Using LEMGD, we estimated the fatigue life for the specimens without and with UIT under the constant-amplitude loading in the stress range of $80 \sim 280$ $\mathrm{MPa}$ and at a stress ratio of 0.1 . In this technique, local surface

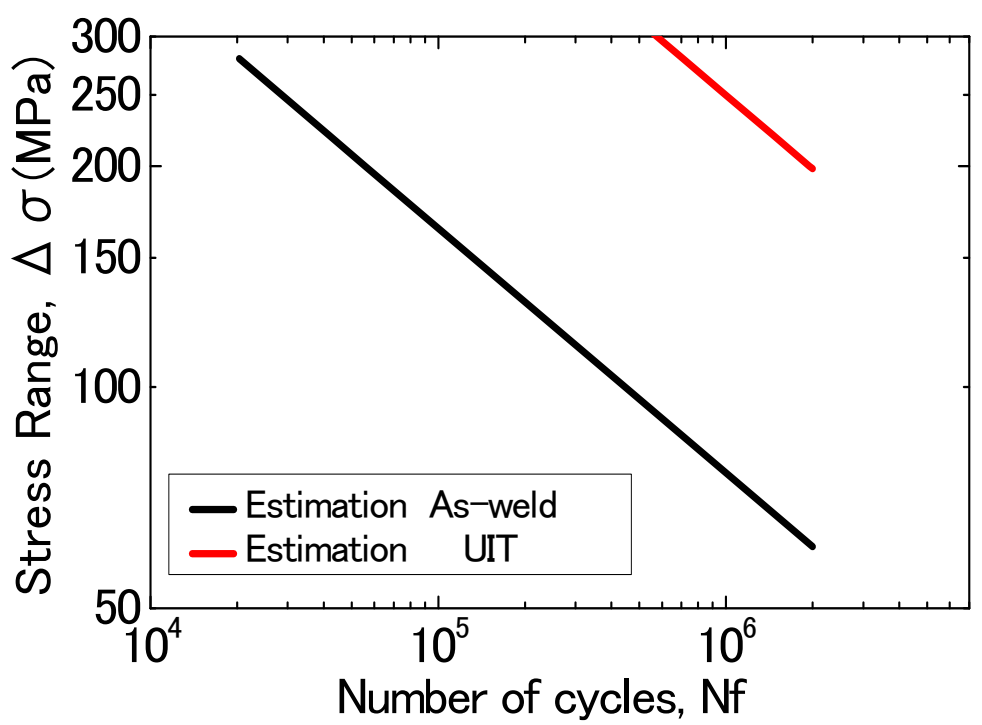

Fig. 8. Estimated S-N curves. stress $\sigma_{\mathrm{L}}$ at the weld toe is represented by Eq.3. In Eq.3, Kt, $\sigma_{\mathrm{N}}$ and $\sigma_{\mathrm{RS}}$ denote stress concentration coefficient, nominal stress and residual stress, respectively. We used 4.07 as Kt and 227MPa as $\sigma$ RS for as-welded , 2.16 as $\mathrm{Kt}$ and -76MPa as $\sigma$ RS for UIT, respectively.

Fig. 8. shows the estimated S-N curves (stress versus number of loading cycles to failure), using LEMGD.

$$
\sigma_{\mathrm{L}}=\mathrm{Kt} \times \sigma_{\mathrm{N}}+\sigma_{\mathrm{RS}}
$$

\section{Analysis of effects of UIT on fatigue strength.}

Comparing of fatigue tests to estimations calculated with surface stress concentration and surface residual stress and without internal residual stress, internal stress can be affect o fatigue life. In high cycle fatigue conditions that the stress range are small, then experiments and estimations are almost same. In this case, internal stress doesn't affect to the fatigue life, and the fatigue life is strongly affected by surface stress conditions, that are surface stress concentration and surface residual stress. In this case, to improve fatigue life of steel structure by UIT, we should control just surface stress conditions, that are surface stress concentration and surface residual stress.

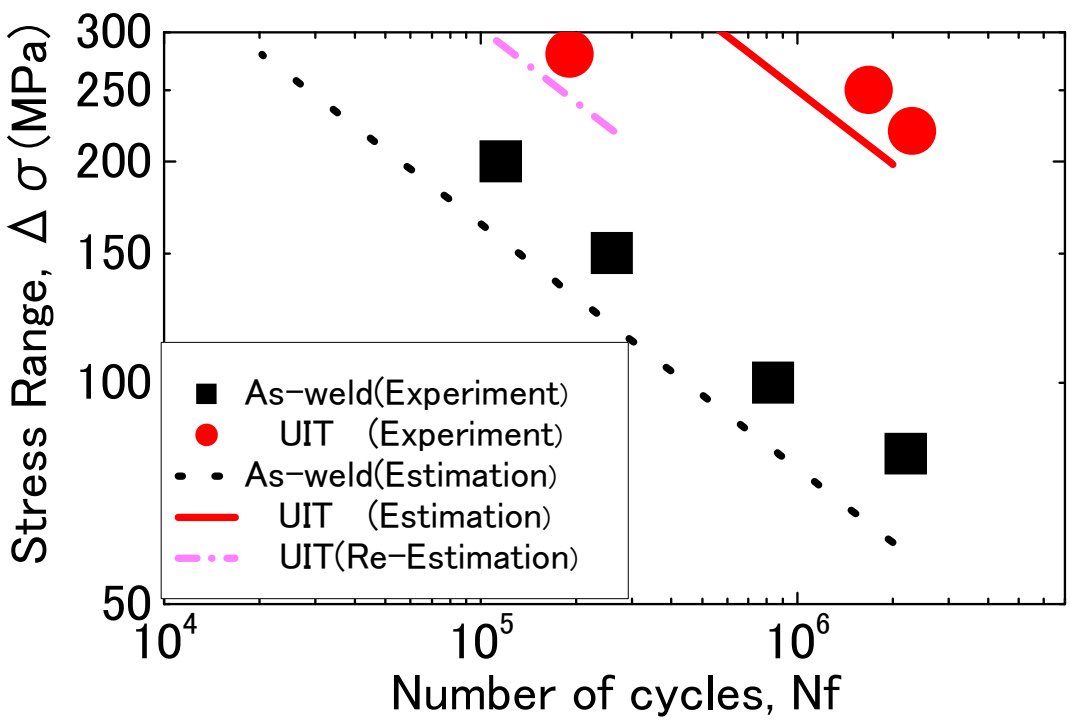

Fig. 9. Experimental and estimated S-N curves. 
On the other hands, in the low cycle fatigue conditions that the stress range is large, the experiment is much smaller than the estimations.

To understand the reason why the experiment are much smaller the estimation in this case, we corrected the estimation of a fatigue life of this case with the surface residual stress measured by $\mathrm{X}$-ray method after the first cycle in fatigue tests and compare the corrected estimation to actual fatigue test. Then the corrected estimation and the actual fatigue test are almost same. The reason why the experiments are much smaller than the predictions in this case was turned out to be that the redistribution occurred because of internal high tensile stress in the first cycle in fatigue tests and the surface residual compressive stress after UIT has changed to tensile stress. In this case, the fatigue life can be affected by the internal stress conditions at near-weld-toe-area, and we should control both surface and internal conditions.

\section{Summary}

Internal stress distribution was clarified on UIT treated cruciform welded joints by neutron diffraction method. Comparing the fatigue experiments to predictions calculated with the results of the experimental investigations, the effect of UIT on fatigue life is turned out that in mild fatigue tests conditions, the fatigue life is strongly affected by the surface stress conditions. In this case, to improve fatigue life of steel structure, we should control just surface stress conditions by UIT. On the other hands, in severe fatigue tests conditions, the fatigue life is not only affected by the surface stress conditions, but also can be affected by the internal stress conditions. In this case, we should control both surface and internal stress conditions by UIT.

\section{References}

[1] H.Tanaka, K.Akita, Y.Sano, S.Ohya, A.Moriai, K.Kajiwara, M.Sato, Non-destructive Measurement of Residual Stress Depth Distribution on Laser-peened Material, Proceedings of the Japan society of Materials science.(2005)155-156.

[2] T.Kasuya, K.Sasaki, Flux Cored Wire for Steel Sheet with Fatigue Strength Improvement, Quarterly Journal of the Japan Welding Society. 27(2) .(2009)158s-162s.

[3] T. Tominaga, C. Miki, Effect of Steel Strength and Ms Temperature on Fatigue Performance of Low Temperature Transformation Electrode, IIW-Doc.- XIII .(2002)1953-02.

[4] M.Mochizuki, Y.Mikami, M.Iyota, H.Inoue, T.Kasuya, Effect of Low Temperature Transformation Expansion on Residual Stress of High Strength Steel Welds, The Annual International Offshore and Polar Engineering Conference (ISOPE). (2009)

[5] T.Kasuya, Flux Cored Wire for Fatigue Strength Improvement,SX-1LD, Journal of the Japan Welding Society.78(4). (2009)244-247.

[6] E. S. Statnikov, Comparison of Efficiency and Processibility of Post-Weld Deformation Method for Increase in Fatigue Strength of Welded Joints, IIW Doc.-XIII. (1997)1668-97.

[7] E. S. Statnikov, Guide for application of ultrasonic impact treatment for improving fatigue life of welded structure, IIW/IIS Doc.-XIII. (1999)1757-99.

[8] T.Nose, H.shimanuki, K.Nakajima, T.Suzuki, Fatigue Strength Improvement Mecanisum in Welded Joint by the Ultrasonic Impact Treatment, Proceedings of the National Symposium on Welding Mechanics and design. (2006)219-222.

[9] T.Nose, H.shimanuki, Experiment and Analysis of Influence of Ultrasonic Peening on Fatigue Life in Pad Welded joints, Transactions of Japan Society of Mechanical Engineers. (2008)166-168.

[10] T.Suzuki, M.Imafuku, T.Okawa, H.shimanuki, T.Nose, H.suzuki, A. Moriai, Residual stress measurement of UIT(Ultrasonic Impact Treatment) treated steel plate by neutron diffraction method, Proceedings of The $44^{\text {th }}$ Symposium on X-Ray Studies on Mechanical Behavior of Materials. (2010)56-60. 
[11] T.Suzuki, N.Oota, T.Okawa, H.shimanuki, T.Nose, S.Haujo, M. Itou, K.Aizawa, Residual stress measurement of UIT(Ultrasonic Impact Treatment) treated steel plate by neutron diffraction method, Proceedings of The $45^{\text {th }}$ Symposium on X-Ray Studies on Mechanical Behavior of Materials. (2011)83-87.

[12] Isamu Tsuju, Estimation of stress concentration factor at weld toe of non-load carrying fillet welded joints, The Japan Society of Naval Architects and Ocean Engineers. (1990)241-251.

[13] T.Nose, Ultrasonic Peenig Method for Fatigue Strength Improvement, Journal of the Japan Welding Society. (2008)210-213.

[14] T.Nose, T.Okawa, Approaches for Fundamental Principles2:Total Solution for Fatigue of Steel,NIPPON STEEL TECHNICAL REPORT No.101. (2012)158-163. 